\title{
Q Crescimento inicial e composição química de Pereskia aculeata Miller cultivada em diferentes luminosidades
}

Carla Regina Amorim dos Anjos Queiroz ${ }^{1}$

Cristina Maria dos Santos Moraes ${ }^{2}$

Reginaldo Rodrigues de Andrade ${ }^{3}$

Luiz Carlos Pavani ${ }^{4}$

\section{Resumo}

A Pereskia aculeata Miller é uma hortaliça não convencional cujo consumo pode fornecer à dieta substâncias nutritivas e antioxidantes, cujos teores podem ser influenciados pelas condições de cultivo. As plantas foram cultivadas a partir de sementes em sombra artificial, em meia sombra e sem sombra. Avaliou-se o crescimento em termos de massa e unidades estruturais e quantificou-se o resíduo mineral, proteínas, lipídeos, fibra em detergente neutro, fenóis e atividade antioxidante. Há influência do sombreamento no crescimento, no teor de nutrientes e metabólitos secundários. As plantas sem sombra apresentaram maior altura, número de folhas, diâmetro do colo, massa seca de caules e folhas e atividade antioxidante. As plantas totalmente sombreadas apresentaram maiores teores de cinzas, lipídeos e proteínas. Para todos os parâmetros avaliados, os teores quantificados em folhas foram maiores que em caules.

Palavras-chave: Análise de crescimento. Antioxidantes. Composição centesimal. Fenóis totais. Ora-pro-nóbis.

\section{Introdução}

A Ora-pro-nóbis (OPN), Pereskia aculeata Miller, é uma cactácea que pode crescer em cercas ou espaldeiras (PEREIRA et al., 2011; TOFANELLI; RESENDE, 2011) ou ainda formar moitas; é de fácil reprodução e cultivo por sua rusticidade e resistência ao déficit hídrico (MADEIRA; SILVEIRA, 2010; QUEIROZ, 2012). Em condições adequadas, observa-se crescimento vegetativo intenso, que proporciona abundância de folhas próprias para consumo (SANTOS et al., 2011), como hortaliça (in natura) ou como ingrediente em pratos elaborados, contribuindo para o suprimento das necessidades nutricionais diárias (ROCHA et al., 2008; TAKEITI et al., 2009; SILVA JÚNIOR et al., 2010).

A análise química das plantas permite identificar e quantificar a presença de substâncias de interesse nutricional e/ou terapêutico, como já relatado para folhas de Ora-pro-nóbis em plantas cujas condições de cultivo não foram especificadas em relação ao teor de proteínas (ALMEIDA FILHO; CAMBRAIA, 1974; TAKEITI et al., 2009), composição de aminoácidos (ALBUQUERQUE et al., 1991; TAKEITI et al., 2009), minerais (TAKEITI et al., 2009; SILVA et al., 2010) e atividade de

\footnotetext{
1 Instituto Federal do Triângulo Mineiro, Campus Uberlândia, professora. Uberlândia, Minas Gerais, Brasil. carlaregina@iftm.edu.br. (34)3233-8851. Fazenda Sobradinho, s/n, Zona Rural, Uberlândia, MG. CEP: 38400-970, Caixa Postal 1020.

2 Instituto Federal do Triângulo Mineiro, graduada em Tecnologia em Alimentos. cris_santosmoraes@hotmail.com.

3 Instituto Federal do Triângulo Mineiro, Campus Uberlândia, professor. Uberlândia, Minas Gerais, Brasil. reginaldoandrade@iftm. edu.br. (34)3233-8851. Fazenda Sobradinho, s/n, Zona Rural, Uberlândia, MG. CEP: 38400-970, Caixa Postal 1020.

4 Universidade Estadual Paulista "Júlio de Mesquita Filho" - Campus de Jaboticabal, professor aposentado. Jaboticabal, São Paulo, Brasil.pavani.Ic@gmail.com.
} 
extratos (VALENTE et al., 2007; SARTOR et al., 2010).

De ocorrência ampla nos vegetais, os fenóis são substâncias que possuem ação antioxidante, ou seja, têm a capacidade de inibir a peroxidação lipídica, a lipooxigenase, sequestrar radicais livres e quelar metais de transição. Resultantes do metabolismo secundário das plantas, os compostos fenólicos podem ter seu teor alterado em função de condições ambientais e estresses. Quando adicionados à alimentação humana, essas substâncias agem reduzindo o risco de desenvolvimento de doenças degenerativas associadas ao envelhecimento, tais como arteriosclerose e câncer (SOUSA et al., 2007; ÂNGELO; JORGE, 2007; GOBBO-NETO; LOPES, 2007).

Entretanto, sabe-se que fatores climáticos, endógenos, bióticos, abióticos e até fatores técnicos, como forma de plantio e cultivo influenciam no desenvolvimento das plantas e na produção de princípios ativos (MARCHESE; FIGUEIRA, 2005; GOBBO-NETO; LOPES, 2007). Por essa razão, é importante associar às características químicas quantificadas a especificidade da condição de desenvolvimento das plantas, de forma que seja possível indicar formas de manejo agronômico que venham a maximizar sua produção de acordo com os interesses de uso (MACIEL et al., 2002).

O crescimento das plantas ocorre em função da atividade fotossintética e da absorção de nutrientes minerais e pode ser entendido como um aumento progressivo e irreversível de qualquer atributo físico (PEIXOTO, 2010), o qual, por sua vez, pode ser avaliado por meio da quantificação de dimensões lineares, superficiais e volumétricas, massa e contagem de unidades estruturais, além das razões entre tais parâmetros (BENINCASA, 2003). A avaliação do crescimento de mudas pode ser utilizada para prever o grau de tolerância da espécie ao sombreamento (SCALON et al., 2003), considerando-se que mesmo as plantas tolerantes possuem maior produção de massa seca a pleno sol (FELFILI et al., 1999). A análise de crescimento de plantas em condições específicas de luminosidade procura identificar espécies tolerantes para sobrevivência em áreas de reflorestamento ou mesmo manejo adequado em consórcios (CAMPOS; UCHIDA, 2002; MORAIS et al., 2003). Em relação à OPN, não foi encontrada literatura que apresente características químicas ou de crescimento quando exposta a diferentes níveis de luminosidade, embora haja relatos de que pode crescer em diversos ambientes, desde sombreados até pleno sol (SCHEINVAR, 1995; SCARANO et al., 2001; CALVENTE et al., 2005; CALVENTE; ANDREATA, 2007).

Objetivou-se, neste estudo, avaliar o crescimento inicial das plantas de Ora-pro-nóbis, cultivadas a partir de sementes, em diferentes níveis de sombreamento, e analisar quimicamente a composição de suas folhas e caules.

\section{Material e métodos}

As sementes utilizadas para o cultivo foram obtidas de frutos de Ora-pro-nóbis de matriz existente no jardim botânico experimental da Universidade Federal de Uberlândia. Frutos maduros foram abertos manualmente com auxílio de lâminas de corte e as sementes retiradas foram lavadas com água corrente e deixadas à sombra, em temperatura ambiente, por dois dias. A semeadura, com 512 sementes, ocorreu em bandejas com 128 células contendo substrato comercial para plantio de hortaliças. Aos 40 dias após a emergência, mudas com igual quantidade de folhas em cada tratamento foram selecionadas para o transplantio. 0 transplantio foi feito para recipientes de 1,7 litros, contendo mistura de terra e esterco curtido de bovino na proporção 2:1. A terra utilizada passou por análise química, a partir da qual se fez a correção de acidez e adubação, com tempo de incubação de 10 dias. Após a calagem, a análise química do solo mostrou os seguintes resultados: $\mathrm{pH}_{\mathrm{H} 2 \mathrm{O}}=5,6$; 
$\mathrm{Al}^{3+}=0,0 ; \mathrm{H}+\mathrm{Al}=3,10 \mathrm{cmol}_{\mathrm{c}} \mathrm{dm}^{-3} ; \mathrm{V} \%=35$ e macronutrientes $\left(\mathrm{cmol}_{\mathrm{c}} \mathrm{dm}^{-3}\right): \mathrm{K}^{+}=0,10, \mathrm{Ca}^{2+}$ $=1,2 ; \mathrm{Mg}^{2+}=0,4$.

O delineamento experimental foi inteiramente casualizado com 3 tratamentos correspondendo aos níveis de sombreamento: SS - sem sombreamento, MS - meia sombra (com sombrite de $50 \%$ de interceptação da radiação solar direta) e TS - totalmente sombreados (ambiente sem incidência de radiação solar direta). Cada tratamento foi constituído por 10 repetições e três plantas por parcela, totalizando 90 plantas, uma por vaso. Os atributos utilizados para avaliação do efeito do sombreamento sobre as plantas foram a altura (A), o diâmetro do colo (DC), o número de galhos por planta (NGP) e o número de folhas por planta (NFP) e a massa seca de caules (MSC) e de folhas (MSF), aos 119 dias após o transplantio, no corte total das plantas. Com essas variáveis, foram determinadas as razões entre a massa de caule e folhas (RCF), entre a altura e o número de folhas (RANF) e entre a altura e o diâmetro do colo (RADC). Após o corte, os caules e folhas foram submetidos à limpeza com detergente (1\%), seguida de lavagem com água corrente, água sanitária 200 ppm e água destilada. A seguir, as amostras foram secas em estufa com circulação forçada de ar a $65{ }^{\circ} \mathrm{C}$, por 72 horas, determinando-se assim a massa seca. Em seguida ao período de secagem, folhas e caules foram triturados e unidos por tratamento, resultando em 6 amostras compostas e homogêneas, armazenadas em frascos de vidro com tampa, mantidos em temperatura ambiente, sem incidência de luz. Foram feitas análises químicas do material seco, em triplicata, a saber: composição centesimal (INSTITUTO ADOLFO LUTZ, 2008), teor de compostos fenólicos totais pelo método Folin-Ciocalteau (SWAIN; HILLIS, 1959) e atividade antioxidante pelo consumo do reagente DPPH (QUEIROZ et al., 2002).

\section{Resultados e discussão}

As plantas de OPN apresentaram 100\% de sobrevivência ao transplantio, indicando que, passados 40 dias da emergência, a espécie apresenta resistência ao estresse provocado pelo procedimento de retirada do substrato e que o tempo necessário para reacomodação das raízes não foi suficiente para provocar dano letal às plantas. A mesma sobrevivência foi observada em relação à condução nas condições sem sombreamento, meia sombra e totalmente sombreado, pois, após 119 dias de condução, todas as plantas encontraram-se vivas e visualmente vigorosas, sem apresentar tombamento do caule.

Houve diferença significativa em todos os parâmetros de crescimento avaliados em função dos tratamentos (Tabela 1). Para o número de folhas por planta (NFP) e para as massas secas de caules (MSC) e folhas (MSF), as plantas cultivadas sem sombreamento (SS) ou meia sombra (MS) apresentaram resultados iguais e maiores que aqueles obtidos nas plantas cultivadas na sombra (TS), em média, 43,2 \pm 8,3 folhas planta $^{-1}$, o que representa três vezes a quantidade de folhas nas plantas totalmente sombreadas. Esse resultado mostra maior eficiência no metabolismo da planta e em translocar fotossintatos, em condição sem sombreamento, assim como observado por Silva et al. (2007) em plantas de cupuaçu. A produção de massa seca em caules e folhas de OPN em condição totalmente sombreada foi apenas $3,2 \%$ e $9,7 \%$ da massa média obtida nos tratamentos em condição sem sombreamento e à meia sombra $\left(9,3 \pm 2,4\right.$ e 5,2 $\pm 1,1$ g planta $\left.{ }^{-1}\right)$, respectivamente. Esse resultado aponta para uma perda significativa nas atividades metabólicas da planta pelo sombreamento extremo. Interessante notar que, embora com o mesmo tempo de cultivo, a MSF das plantas de OPN totalmente sombreadas foi maior que a MSC, indicando que as folhas continham menor fração lenhosa que os caules cultivados em meia sombra e sem sombreamento, visto que nesses dois tratamentos 
a MSC é maior que a MSF. Em relação ao cultivo de plantas de OPN obtidas a partir de estacas, com o tempo de 120 dias de cultivo e com níveis de oferta de água, a massa obtida em plantas cultivadas a partir de sementes é menor, posto que foram obtidas massas secas entre 41 e $54 \mathrm{~g}$ para folhas e entre 77 e $156 \mathrm{~g}$ para caules (QUEIROZ, 2012), indicando a precocidade do desenvolvimento por estaquia, assim como verificado em plantas de boldo (Plectranthus barbatus) (GÖRGEN; RODRIGUES, 2011).

Esses resultados mostram que o sombreamento alterou o metabolismo da OPN, diminuindo o acúmulo de massa em função da redução da fotossíntese. Entretanto, além do fator genético relacionado ao desenvolvimento a partir de sementes e das estacas, é possível que o menor tamanho do vaso também tenha influenciado o desenvolvimento das plantas, por ter sido conduzido em recipiente cerca de 6 vezes menor que o utilizado no experimento conduzido por Queiroz (2012). Resposta semelhante foi obtida aos 158 dias de cultivo em condição de sombreamento para araucária (Araucaria augustifolia) (FRANCO; DILLENBURG. 2007) e aos 720 dias para mudas de pau-brasil (Caesalpinia echinata Lam.) (AGUIAR et al., 2011), com plantas em condição de sombreamento apresentando menor número de folhas e menor massa da parte aérea do que as plantas de controle. Lusk (2004) aponta que espécies tolerantes à sombra ou à pouca luz estão relacionadas a fatores estruturais como tecidos duros, resistentes ao estresse físico e pouco atraentes para inimigos naturais. Essas espécies devem favorecer o acúmulo em detrimento do crescimento, o que justificaria o menor crescimento em altura, diâmetro do colo, massa seca e número de folhas, sem, entretanto, apresentar tombamento ou morte em nenhuma planta de Ora-pro-nóbis.

Tabela 1. Resumo da análise de variância e valores médios \pm desvio padrão para número de folhas (NFP) e de galhos por planta (NGP), altura da planta (A), diâmetro do colo (DC) e massas secas de folhas (MSF), caules (MSC) e plantas de Ora-pro-nóbis cultivadas sem sombreamento (SS), meia sombra (MS) e totalmente sombreadas (TS), aos 119 dias após o transplantio.

\begin{tabular}{|c|c|c|c|c|c|c|c|c|c|}
\hline \multicolumn{10}{|c|}{ Resumo da análise de variância } \\
\hline Variáveis & QM & "F" & CV \% & \multicolumn{2}{|c|}{ Variáveis } & \multicolumn{2}{|c|}{ QM } & "F" & CV \% \\
\hline \#NFP & 26,0331 & $89,3^{* *}$ & 9,6 & \multicolumn{2}{|l|}{$\mathrm{DC}$} & \multicolumn{2}{|c|}{141,0070} & $133,13^{* *}$ & 11,0 \\
\hline "NGP & 0,4690 & $18,62^{* *}$ & 13,9 & \multicolumn{2}{|c|}{ MSF } & \multicolumn{2}{|c|}{73,9213} & $97,52^{* *}$ & 24,2 \\
\hline A & 10449,8670 & $76,4^{* *}$ & 22,2 & \multicolumn{2}{|c|}{ MSC } & 261,0 & & $66,10^{* *}$ & 32,3 \\
\hline \multirow{2}{*}{ Tratamentos } & \#NFP & ${ }^{\#} \mathrm{NGP}$ & & & & & & $\mathrm{SF}$ & MSC \\
\hline & \multicolumn{2}{|c|}{-----(unidades)------ } & \multicolumn{2}{|c|}{$(\mathrm{cm})$} & & m) & & \multicolumn{2}{|c|}{-------(g)------- } \\
\hline SS & $@ 43,9 \pm 9,6$ & $2,0 \pm 0,7 a$ & 58 & $7,1 b$ & & $\pm 0,8 a$ & & $0,7 a$ & $9,3 \pm 1,6 a$ \\
\hline MS & $42,5 \pm 7,1 a$ & $1,1 \pm 0,2 b$ & 82, & $3,8 a$ & 10, & $1,5 \mathrm{~b}$ & & $1,3 a$ & $8,9 \pm 3,1 a$ \\
\hline TS & $14,1 \pm 1,9 b$ & $1,0 \pm 0,0 b$ & 18 & $2,9 c$ & 5 & $0,5 c$ & & $0,2 b$ & $0,3 \pm 0,1 b$ \\
\hline
\end{tabular}

\#Dados transformados em raiz de $\mathrm{x}_{;}{ }^{* *}$ - significativo a $1 \%$ de probabilidade pelo teste $\mathrm{F} ;{ }^{\circledR}$ - médias seguidas de letras minúsculas diferentes na coluna diferem entre si a $5 \%$ de probabilidade pelo teste de Tukey; QM quadrado médio, CV - coeficiente de variação.

Fonte: Elaboração dos autores.

Menor investimento em ramificação foi observado em plantas totalmente sombreadas e em condição de meia sombra, possivelmente um mecanismo para permitir o maior crescimento vertical da planta (FRANCO; DILLENBURG, 2007).

As plantas totalmente sombreadas se desenvolveram significativamente menos em relação à altura e ao diâmetro do colo. 0 maior diâmetro foi alcançado pelas plantas em condição sem sombreamento e a maior altura em condição de meia sombra. Segundo Felfili et al. (1999), resultados de maior crescimento (massa, altura, diâmetro do colo), em condição de meia sombra ou sem sombreamento, são característicos de plantas heliófitas. 
A razão caule/folha (RCF) (Tabela 2) foi igual entre os tratamentos sem sombra e meia sombra, indicando que, nessas condições e estágio de desenvolvimento, a massa de caule é cerca de $70 \%$ maior que a de folhas. Em plantas em condição de total sombreamento, observou-se comportamento inverso, com maior massa acumulada em folhas. Em condição totalmente sombreada, os caules apresentaram em média cerca de $50 \%$ da massa presente em folhas, possivelmente em função de atraso no desenvolvimento. Visualmente, no corte das plantas, os caules desse tratamento ainda estavam em estágio pré-lenhoso, o que significa que estavam verdes por dentro e por fora, e não apresentavam anéis internos de coloração marrom, que indicam o processo de formação de estrutura lenhosa.

Pela razão altura/número de folhas (RANF), detectou-se maior distância entre as folhas das plantas em meia sombra. Esse resultado revelou que a condição de $50 \%$ de redução da incidência direta de luminosidade implicou maior distância entre as gemas, uma vez que, nas plantas de OPN, cada folha emerge em um nó único.

A razão altura/diâmetro do colo (RADC) foi maior nas plantas em condição de meia sombra e não houve diferença entre as plantas cultivadas sem sombreamento e as totalmente sombreadas. Quanto menor essa razão, melhor qualidade de muda para transplantio ao campo, por haver maior equilíbrio entre as partes da planta (SILVA et al., 2007).

Tabela 2. Resumo da análise de variância e valores médios \pm desvio padrão para as razões entre a massa seca de caules e folhas (RCF), entre a altura e o número de folhas (RANF) e entre a altura e o diâmetro do colo (RADC) em plantas de Ora-pro-nóbis cultivadas sem sombreamento (SS), meia sombra (MS) e totalmente sombreado (TS), aos 119 dias após o transplantio.

\begin{tabular}{cccc}
\hline \multicolumn{4}{c}{ Resumo da análise de variância } \\
\hline RCF & QM & "F" & CV \% \\
RANF & 4,1813 & $146,24^{* *}$ & 13,1 \\
RADC & 1,7670 & $23,47^{* *}$ & 17,0 \\
\hline \multirow{2}{*}{ Tratamentos } & 49,4830 & $34,4^{* *}$ & 22,2 \\
\cline { 2 - 4 } & RCF & RANF & RADC \\
\cline { 2 - 4 } SS & g g-1 $^{-1}$ & cm unidade & mm $^{-1}$ \\
MS & $1,7 \pm 0,2 \mathrm{a}$ & $1,5 \pm 0,2 \mathrm{~b}$ & $4,8 \pm 0,5 \mathrm{~b}$ \\
TS & $1,7 \pm 0,2 \mathrm{a}$ & $2,1 \pm 0,4 \mathrm{a}$ & $7,9 \pm 1,9 \mathrm{a}$ \\
& $0,5 \pm 0,1 \mathrm{~b}$ & $1,3 \pm 0,1 \mathrm{~b}$ & $3,5 \pm 0,6 \mathrm{~b}$ \\
\hline
\end{tabular}

\#Dados transformados em raiz de $\mathrm{x}$; letras minúsculas diferentes na linha representam diferença significativa a $1 \%$ de probabilidade, @ - médias seguidas de letras minúsculas diferentes na coluna diferem entre si a 5\% de probabilidade pelo teste de Tukey QM = quadrado médio, $\mathrm{CV}$ = coeficiente de variação. Fonte: Elaboração dos autores.

Em função de a massa seca resultante ter sido pequena nas plantas conduzidas na ausência de luz solar direta (TS), as repetições foram unidas em uma amostra composta por tratamento, cuja análise química de nutrientes revela alta quantidade de cinzas tanto em caules quanto em folhas (Figura 1). 0 teor de cinzas em hortaliças convencionais é geralmente menor que $10 \%$ (base seca) (NEPA/TACO, 2011), o que não se observa nas folhas da OPN, cujo resultado revelou teores de cinzas entre 18 e 32\% em base seca. Esse resultado está em acordo com o relatado por Queiroz (2012), cerca de 21\%, e por Magalhães et al. (2011), entre 13,5 e 26,1\% para folhas de diferentes matrizes.

As diferenças observadas ocorrem em função de as plantas serem de espécies diferentes e por isso devem apresentar necessidades nutricionais e metabólicas diferentes. Entre as hortaliças conven- 
cionais também há diferenças tanto entre espécies quanto em função das condições de cultivo, como observado em cultivares de alface sob sombreamentos (AQUINO et al., 2007).

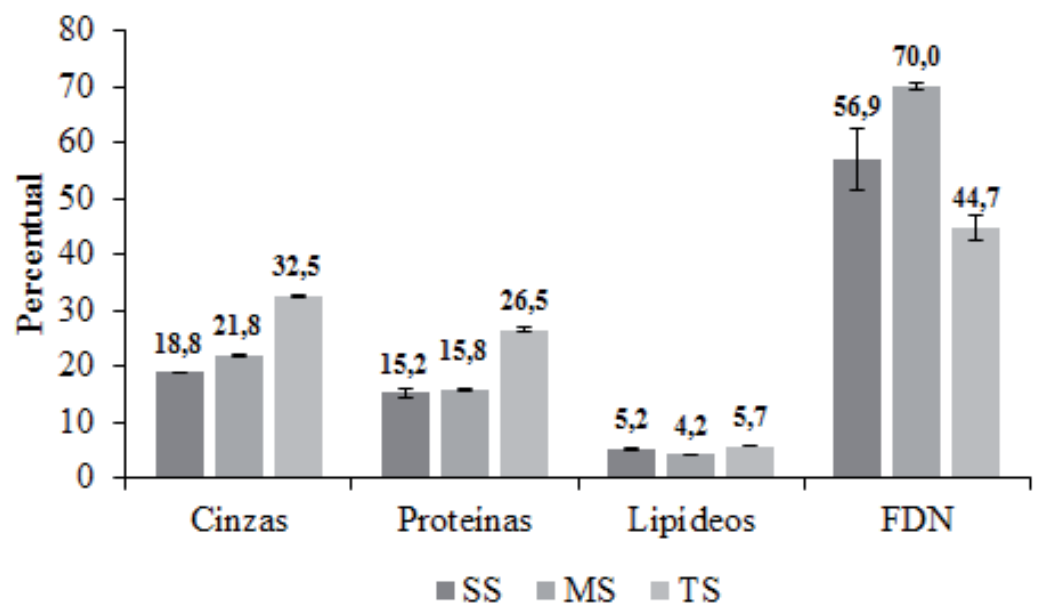

Figura 1. Composição química de folhas de Ora-pro-nóbis, aos 119 dias de cultivo, em função de níveis de sombreamento (SS - sem sombreamento; MS - meia sombra; TS - totalmente sombreado), em base seca a $105^{\circ} \mathrm{C}$.

Fonte: Elaboração dos autores.

O maior teor de proteínas nas folhas foi encontrado em condição totalmente sombreada (Figura 1 ), que superou em cerca de $74 \%$ o teor nas folhas em meia sombra e em cerca de $68 \%$ em plantas sem sombreamento. Os resultados obtidos neste trabalho para condição de totalmente sombreado e meia sombra estão de acordo com os relatados na literatura para essa planta, entre 14 e $21 \%$ por Queiroz (2012), e entre 15,2 e 30,1\% em cinco plantas matrizes, por Magalhães et al. (2011).

Os lipídeos nas folhas de OPN foram a menor fração obtida, com teores entre 4,2 e 5,7\% em base seca, percentuais próximos aos já determinados para OPN (MAGALHÃES et al., 2011; QUEIROZ, 2012). Em função de diferentes luminosidades, houve diferença de $26,3 \%$ entre o totalmente sombreado (maior teor) e a meia sombra (menor teor). À semelhança do que foi observado para o teor de cinzas e de proteínas, o teor de lipídeos também foi maior na ausência de radiação solar direta.

0 teor de fibra em detergente neutro (FDN) foi maior nas plantas sob meia sombra $(70,0 \%)$ e menor nas totalmente sombreadas (44,7\%). Esse resultado, em conjunto com os anteriores, indica que as plantas de OPN apresentam modificações metabólicas para ajuste e manutenção do desenvolvimento em função das condições de intensidade luminosa.

Nos caules, os níveis de sombreamento modificaram a composição química de forma similar ao que ocorreu nas folhas (Figura 2), em relação a proteínas, cinzas e FDN, ou seja, maiores teores no tratamento totalmente sombreado, além de os teores de FDN terem sido superiores aos de cinzas, esses aos de proteínas, que, por sua vez, superaram os de lipídeos. Maior teor de cinzas do que de proteínas, em todas as condições de cultivo, tanto para folhas quanto para caules, mostra que a OPN pode ser uma fonte importante de sais minerais se comparada a outras hortaliças de consumo usual. O teor de cinzas em caules nas plantas cultivadas em condição sem sombreamento e meia sombra, entre 7 e $9 \%$, é próxima à determinada em plantas de OPN cultivadas com controle na oferta de água (6 e 8\%) (QUEIROZ, 2012). Na condição totalmente sombreada, o teor de cinzas em caules foi mais que o dobro do obtido sem sombreamento e à meia sombra e apenas $75 \%$ do teor em folhas na mesma condição. 


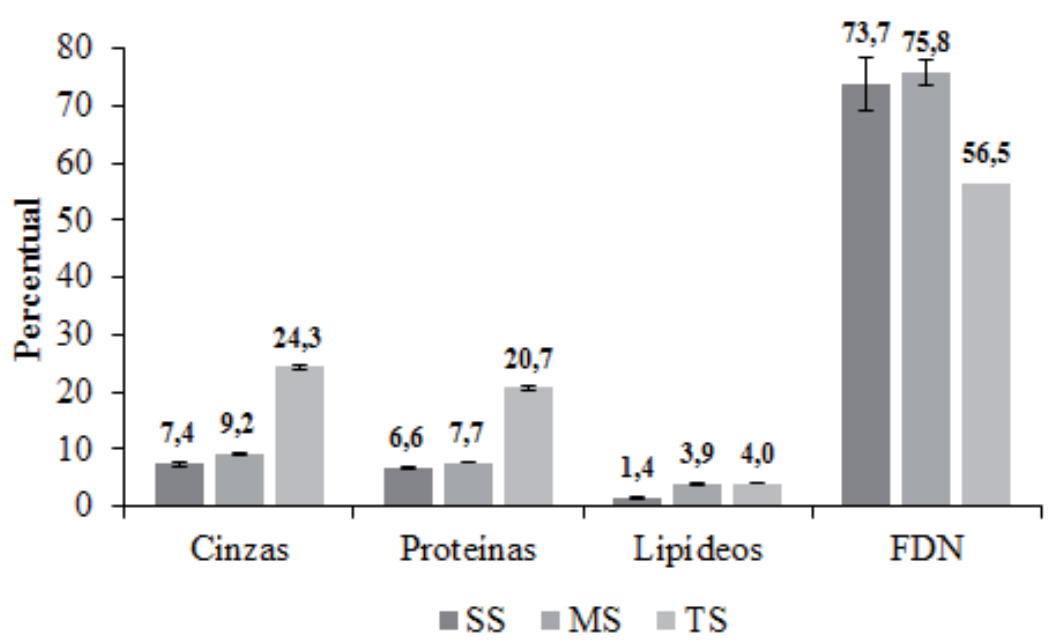

Figura 2. Composição química de caules de Ora-pro-nóbis, aos 119 dias de cultivo, em função de níveis de sombreamento (SS - sem sombreamento; MS - meia sombra; TS - totalmente sombreado), em base seca a $105^{\circ} \mathrm{C}$

Fonte: Elaboração dos autores.

O teor de proteínas em caules é menor que em folhas em todos os sombreamentos testados e na condição totalmente sombreada equivaleu a $78 \%$ do teor em folhas. Os resultados obtidos nas plantas em meia sombra e sem sombreamento estão no intervalo já descrito para plantas de OPN (de 4 a 9\%) (QUEIROZ, 2012).

Entre os nutrientes avaliados, os lipídeos foram a menor fração entre os constituintes das plantas de OPN, tanto em caules quanto em folhas. Nos caules, o menor teor obtido verificou-se nas plantas sem sombreamento (cerca de $1,4 \%$ ), e, entre os tratamentos à meia sombra e totalmente sombreado, os teores foram muito próximos. Diferentemente do teor de lipídeos obtido para folhas (Figura 1), em que a máxima diferença nos três sombreamentos foi de $26 \%$, o teor de lipídeos sem sombreamento nos caules foi cerca de $35 \%$ do teor obtido nos demais sombreamentos.

A fibra em detergente neutro (FDN) apresentou resultados maiores nos tratamentos sem sombreamento. Como é possível o aproveitamento desse vegetal também para alimentação animal, destaca-se a possibilidade do seu uso em função dos teores obtidos na média dos tratamentos sem sombreamento e à meia sombra $(63,5 \% \pm 8,0$ - folhas; 74,8 $\pm 3,7$ - caules), visto serem maiores que a média de 136 forrageiras usadas para elaboração de ração animal $(54,4 \pm 5,1)$ (SANTOS et al., 2010) e possuírem proteína bruta também maior que a média apresentada no estudo de Santos et al. (2010) (13,3\%).

Tanto o teor de fenóis totais (Figura 3) quanto a atividade antioxidante (AA) (Figura 4) foram maiores em folhas do que em caules, em todos os sombreamentos, indicando que a presença de substâncias com capacidade de ação antioxidante está presente em maior teor nas folhas do que nos caules de OPN. As substâncias antioxidantes são resultado do metabolismo secundário das plantas e geralmente aumentam quando em condição de estresses, pois agem como protetores do vegetal, como em presença de radiações ultravioleta (GOBBO-NETO; LOPES, 2007; ÂNGELO; JORGE, 2007). Por essa razão, os resultados apontam para maior atividade antioxidante na condição sem sombreamento. Em folhas, a atividade antioxidante foi cerca de 2,3 vezes maior sem sombreamento do que nas plantas totalmente sombreadas; em caules, a diferença de atividade antioxidante entre 0 tratamento sem sombreamento e o totalmente sombreado foi de apenas $20 \%$. 


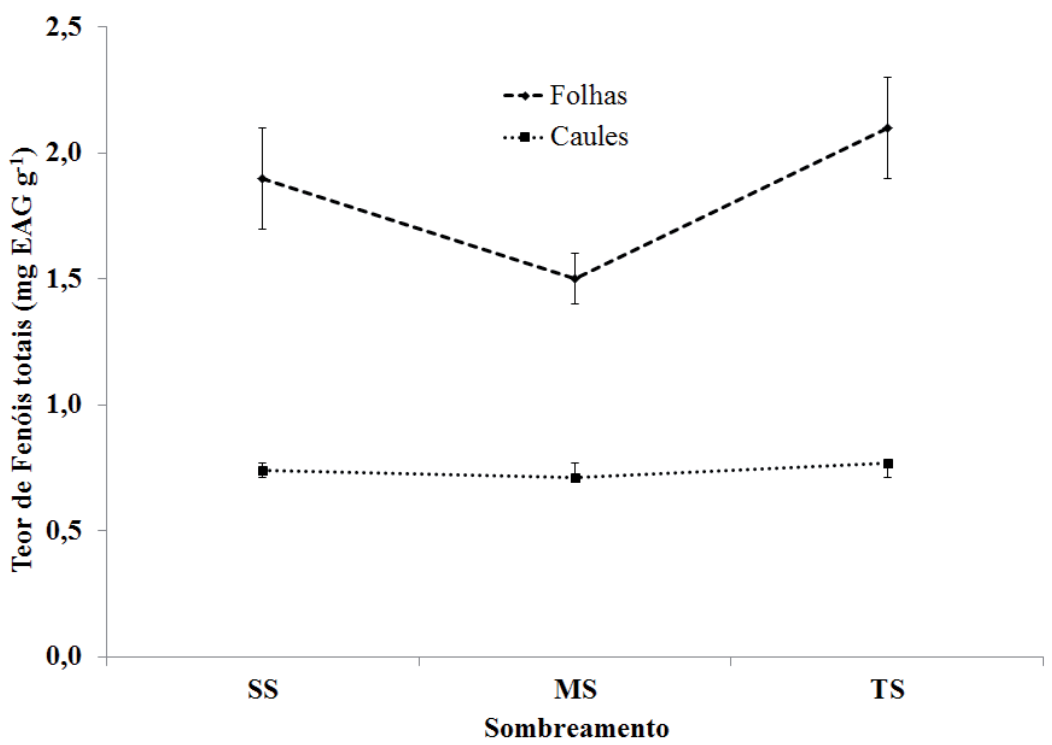

Figura 3. Teor de fenóis em folhas e caules de Ora-pro-nóbis, aos 119 dias de cultivo sob níveis de sombreamento (SS - sem sombreamento; MS - meia sombra; TS - totalmente sombreado).

Fonte: Elaboração dos autores.

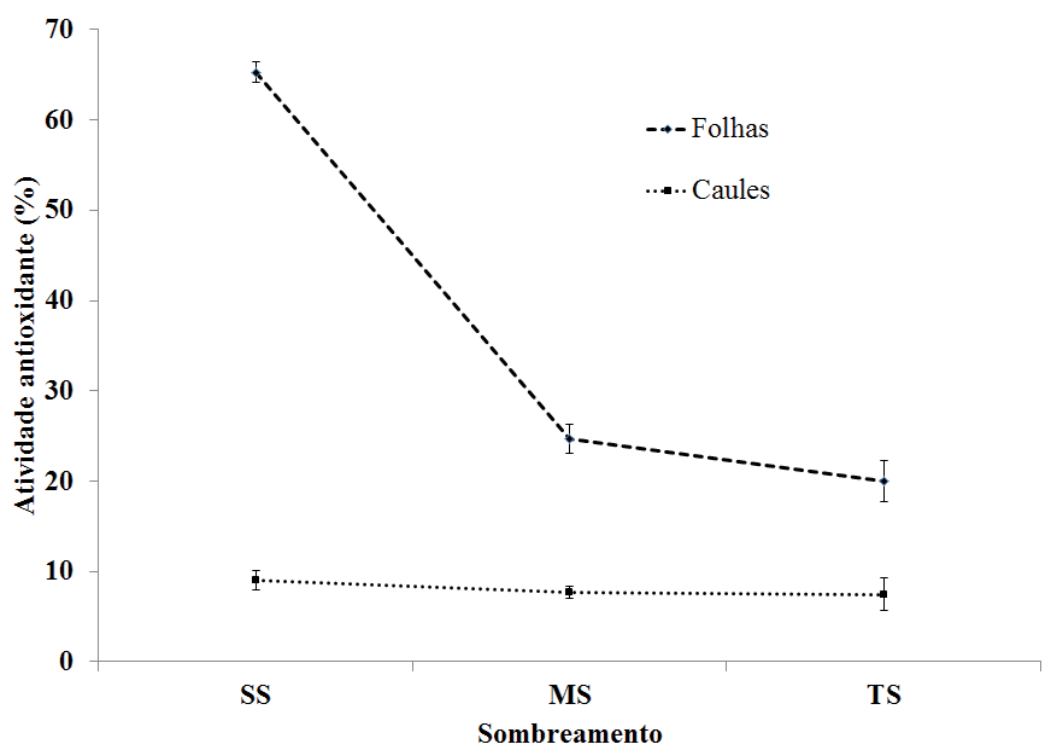

Figura 4. Percentual de atividade antioxidante em folhas e caules de Ora-pro-nóbis, aos 119 dias de cultivo sob níveis de sombreamento (SS - sem sombreamento; MS - meia sombra; TS - totalmente sombreado).

Fonte: Elaboração dos autores.

As hortaliças de consumo usual como a alface, a rúcula e o almeirão, cultivadas de forma convencional e orgânica, apresentam menores teores de fenóis totais (entre 126,84 \pm 4,46 mg EAG $100 \mathrm{~g}^{-1}$ e 81,04 $\pm 3,64 \mathrm{mg}$ EAG $100 \mathrm{~g}^{-1}$ ) (ARBOS et al., 2010) que as folhas de OPN em todos os

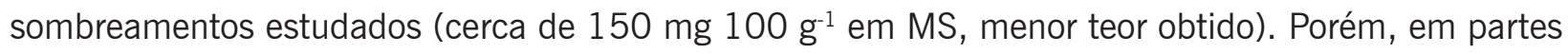
de cinco plantas medicinais analisadas por Sousa et al. (2007), o teor de fenóis totais foi maior (entre 11,55 \pm 0,40 $\mathrm{mg} \mathrm{EAG} \mathrm{g}^{-1}$ e 97,60 $\pm 0,70 \mathrm{mg} \mathrm{EAG} \mathrm{g}^{-1}$ ) que o obtido nas partes da OPN. Esse resultado indica que as folhas da hortaliça não convencional OPN são uma fonte potencial dessas substâncias, cuja ação está relacionada à proteção dos organismos que as consomem, em função da ação antioxidante. 


\section{Conclusão}

As plantas de Ora-pro-nóbis, em estágio inicial de desenvolvimento, apresentam crescimento diferenciado em função da exposição a diferentes luminosidades, apresentando maior crescimento em condições sem sombreamento e sob meia sombra. Em folhas, principal produto da planta de consumo tradicional, os teores de cinzas e proteínas foram maiores em plantas sombreadas (meia sombra e totalmente sombreadas) e a atividade antioxidante maior em folhas sem sombreamento.

\section{Pereskia aculeata Miller initial growth and chemical composition grown in different light conditions}

\section{Abstract}

Pereskia aculeata Miller is an unconventional vegetable whose consumption can provide dietary nutrients and antioxidants, both influenced by culture conditions. Plants were grown from seeds under artificial shade, half shadow and without shadow. We evaluated the growth in terms of mass and structural units and quantified mineral residue, proteins, lipids, neutral detergent fiber, phenolics and antioxidant activity. There is influence of shading on growth, nutrient content and secondary metabolites. Unshaded plants had higher height, leaves, stem diameter, dry mass of stems and leaves and antioxidant activity. The fully shaded plants had higher contents of ash, lipids and proteins. For all parameters evaluated, levels quantified in leaves were higher than in stems.

Keywords: Antioxidants. Growth analysis. Phenolic content. Proximate composition. Ora-pro-nóbis.

\section{Referências}

AGUIAR, F. F. A.; KANASHIRO, S.; TAVARES, A. R.; NASCIMENTO, T. D. R. do; ROCCO, F. M. Crescimento de mudas de pau-brasil (Caesalpinia echinata Lam.), submetidas a cinco níveis de sombreamento. Revista Ceres, Viçosa, v.58, n. 6, p. 729-734, 2011.

ALBUQUERQUE, M. G. P. T.; SABAA SRUR, A. U. O.; FREIMAN, L. O. Composição centesimal e escore de amino-ácidos em três espécies de ora-pro-nóbis (Pereskia aculeata Mill., P. bleu, P. pereskia (L) Karsten). Boletim SBCTA, Campinas, v. 25, n. 1, p. 7-12, 2001.

ALMEIDA FILHO, J.; CAMBRAIA, J. Estudo do valor nutritivo do "Ora-Pro-Nobis". Revista Ceres, Viçosa, MG, v. 21, n. 114, p. 105-111, 1974.

ÂNGELO, P. M.; JORGE, N. Compostos fenólicos em alimentos: uma breve revisão. Revista do Instituto Adolfo Lutz, São Paulo, v. 66, n.1, p. 232-240, 2007.

AQUINO, L. A.; PUIATTI, M.; ABAURRE, M. E. O.; CECON, P. R.; PEREIRA, P. R. G.; PEREIRA, F. H. F.; CASTRO, M. R. S. Produção de biomassa, acúmulo de nitrato, teores e exportação de macronutrientes da alface sob sombreamento. Horticultura Brasileira, Brasília, DF, v. 25, n. 3, p. 381-386, 2007.

ARBOS, K. A.; FREITAS, R. J. S.; STERTZ, S. C.; DORNAS, M. F. Atividade antioxidante e teor de fenólicos totais em hortaliças orgânicas e convencionais. Ciência e Tecnologia de Alimentos, Campinas, v. 30, n. 2, p. 501-506, 2010. 
BENINCASA, M. M. P. Análise de crescimento de plantas. Jaboticabal, SP: FUNEP, 2003. 42 p.

CALVENTE, A. M.; FREITAS, M. de F.; ANDREATA, R. H. P. Listagem, distribuição geográfica e conservação das espécies de cactaceae no estado do Rio de Janeiro. Rodriguésia, Rio de Janeiro, v. 56, n. 87, p. 141-162, 2005.

CALVENTE, A. M.; ANDREATA, R. H. P. The cactaceae of the natural municipal park of prainha, Rio de Janeiro, Brazil: taxonomy and conservation. Journal of the Botanical Research Institute of Texas, Texas, v. 1, n. 1, p. 529-548, 2007.

CAMPOS, M. A. A.; UCHIDA, T. Influência do sombreamento no crescimento de mudas de três espécies amazônicas. Pesquisa Agropecuária Brasileira, Brasília, v. 37, n. 3, p. 281-288, 2002.

FELFILI, J. M.; HILGBERT, L. F.; FRANCO, A. C.; SOUSA-SILVA, J. C.; RESENDE, A. V.; NOGUEIRA, M. V. P. Comportamento de plântulas de Sclerolobium paniculatum Vog. var. rubiginosum (Tul.) Benth. sob diferentes níveis de sombreamento, em viveiro. Revista Brasileira de Botânica, São Paulo, v. 22, n.2 (suplemento), p. 297-301, 1999.

FRANCO, A. M. S.; DILLENBURG, L. R. Ajustes morfológicos e fisiológicos em plantas jovens de Araucaria angustifolia (Bertol.) Kuntze em resposta ao sombreamento. Hoehnea, São Paulo, v. 34, n. 2, p. 135-144, 2007.

GOBBO-NETO, L.; LOPES, N. P. Plantas medicinais: fatores de influência no conteúdo de metabólitos secundários. Química Nova, São Paulo, v. 30, n. 2, p. 374-381, 2007.

GÖRGEN, L. V.; RODRIGUES, L. V. Comparação de métodos de propagação de Plectranthus barbatus via curvas de crescimento de biomassa fresca em estufa. 2011. 15 f. Monografia (Graduação em Agronomia). Universidade de Brasília, Brasília.

INSTITUTO ADOLFO LUTZ. Procedimentos e determinações gerais. In: LUTZ, I. A. Métodos Físico-químicos para análise de alimentos. 4.ed./1.ed. digital. São Paulo: Instituto Adolfo Lutz, v. 1, 2008. Cap. 4, p. 1020.

LUSK, C. H. Leaf area and growth of juvenile temperate evergreens in low light: species of contrasting shade tolerance change rank during ontogeny. Functional Ecology, London, v. 18, p. 820-828, 2004.

MAGALHÃES, R. O. Avaliação físico-química de folhas de ora-pro-nóbis de plantas catalogadas no município de Uberlândia, MG. In: SEMINÁRIO DE INICIAÇÃO CIENTíFICA E INOVAÇÃO TECNOLÓGICA, 1, Uberlândia, 2011. Anais... Uberlândia: IFTM, SIN, 2011.

MACIEL, M. A. M.; PINTO, A. C.; VEIGA JÚNIOR, V. F.; GRYNBERG, N. F.; ECHEVARRIA, A. Plantas medicinais: a necessidade de estudos multidisciplinares. Química Nova, São Paulo, v. 25, n. 3, p. 429-438, 2002.

MADEIRA, N. R.; SILVEIRA, G. S. R. Ora-pro-nóbis. Globo Rural, São Paulo, v. 294, p. 100-101, 2010.

MARCHESE, J. A.; FIGUEIRA, G. M. O uso de tecnologias pré e pós-colheita e boas práticas agrícolas na produção de plantas medicinais e aromáticas. Revista Brasileira de Plantas Medicinais, Paulínia, v.7, n.3, p.86-96, 2005. 
MORAIS, H.; MARUR, C. J.; CARAMORI, P. H.; RIBEIRO, A. M. de A.; GOMES, J. C. Características fisiológicas e de crescimento de cafeeiro sombreado com guandu e cultivado a pleno sol. Pesquisa Agropecuária Brasileira, Brasília, v. 38, n. 10, p. 1131-1137, 2003.

NEPA/UNICAMP. Tabela Brasileira de Composição de Alimentos - (TACO). 4.ed., Campinas, SP: NEPA-UNICAMP, 2011. 161 p.

PEIXOTO, C. P. Curso de Fisiologia Vegetal. Cruz das Almas, 2010. 177 p.

PEREIRA, R. G. F.; SOUZA, M. R. de M.; GOMES, P. R. Experiências locais e investigação científica na produção do ora-pro-nóbis (Pereskia aculeata Mill.). In: CONGRESSO BRASILEIRO DE AGROECOLOGIA, VII, 2011. Fortaleza, Resumos... Fortaleza, CE.

QUEIROZ, C. R. A. A. Cultivo e composição química de Ora-pro-nóbis (Pereskia aculeata Mill.) sob déficit hídrico intermitente no solo. 2012. 144 fl. Tese (Doutorado). Universidade Estadual Paulista Júlio de Mesquita Filho, Jaboticabal.

QUEIROZ, C. R. A. A.; MORAIS, S. A. L.; NASCIMENTO, E. A. Caracterização dos taninos da aroeira-preta (Myracrodruon urundeuva). Revista Árvore, Viçosa, v. 26, n. 4, p. 485-492, 2002.

ROCHA, D. R. da C.; PEREIRA JÚNIOR, G. A.; VIEIRA, G.; PANTOJA, L.; SANTOS, A. S. dos; PINTO, N. A. V. D. Macarrão adicionado de ora-pro-nóbis (Pereskia aculeata Miller) desidratado. Alimentos e Nutrição, Araraquara, v. 19, p. 459-465, 2008.

SCARANO, F. R.; DUARTE, H. M.; RIBEIRO, K. T.; RODRIGUES, P. J. F. P.; BARCELOS, E. M. B.; FRANCO, A. C.; BRULFET, J.; DELÉENS, E.; LÜTTGE, U. Four sites with contrasting environmental stress in southeastern Brazil: relations of species, life form diversity, and geographic distribution to ecophysiological parameters. Botanical Journal of the Linnean Society, London, v. 136, p. 345364, 2001.

SANTOS, M. V. F.; GÓMEZ CASTRO, A. G.; PEREA, J. M.; GARCÍA, A.; GUIM, A.; PÉREZ HERNÁN$D E Z, M$. Fatores que afetam o valor nutritivo da silagens de forrageiras tropicais. Archivos de Zootecnia, Córdoba, v. 59 (R), p. 25-43, 2010.

SANTOS, G. M.; MAGALHÃES, R. de O.; QUEIROZ, C. R. A. A.; ANDRADE, R. R. de; OLIVEIRA, F. de M.; MORAIS, S. A. L.; PAVANI, L. C. Catalogação de ora-pro-nóbis em cultivo no município de Uberlândia, MG. In: SEMINÁRIO DE INICIAÇÃO CIENTÍFICA DO IFTM, 1, 2011, Uberlândia, MG. Anais... Uberlândia, MG: IFTM, 2011.

SCALON, S. P. Q.; MUSSURY, R. M.; RIGONI, M. R.; SCALON FILHO, H. Crescimento inicial de mudas de Bombacopsis glabra (Pasq.) A. Robyns sob condição de sombreamento. Revista Árvore, Viçosa, v. 27, n. 6, p.753-758, 2003.

SCHEINVAR, L. Flora Ilustrada Catarinense: Cactaceas. Itajaí, SC, v. 1, 1995.

SOUSA, C. M. de M.; SILVA, H. R.; VIEIRA JÚNIOR, G. M.; AYRES, M. C. C.; COSTA, C. L. S.; ARAÚJO, D. S.; CAVALCANTE, L. C. D.; BARROS, E. D. S.; ARAÚJO, P. B. M.; BRANDÃO, M. S.; CHAVES, M. H. Fenóis totais e atividade antioxidante de cinco plantas medicinais. Química Nova, São Paulo, v. 30, n. 2, p. 351-355, 2007. 
SARTOR, C. F. P.; AMARAL, V.; GUIMARÃES, H. E. T.; BARROS, K. N.; FELIPE, D. F.; CORTEZ, L. E. R.; VELTRINI, V. C. Estudo da ação cicatrizante das folhas de Pereskia aculeata. Revista Saúde e Pesquisa, Maringá, v. 3, n. 2, p. 149-154, 2010.

SILVA, D. B. ; AGOSTINI-COSTA, T. da S.; VIEIRA, R. F.; ALVES, R. de B. das N.; GOMES, I. da S.; COSTA, F. V. da; ALVES, V. C. Proteína bruta e teor de minerais em duas espécies de ora-pro-nóbis (Pereskia aculeata Mill. e P. grandifolia Haw). In: CONGRESSO BRASILEIRO DE GASTRONOMIA, 3.; SIMPÓSIO REGIONAL DE CIÊNCIA E TECNOLOGIA, 1., 2010, Brasília, DF. Anais... Brasília: UNB:CET; SBCTA, 2010. p. 1-4.

SILVA, R. R.; FREITAS, G. A. de; SIEBENEICHLER, S. C.; MATA, J. F. da; CHAGAS, J. R. Desenvolvimento inicial de plântulas de Theobroma grandiflorum (Willd. ex Spreng.) Schum. sob influência de sombreamento. Acta Amazônica, Manaus, v. 37, n. 3, p. 365-370, 2007.

SILVA JÚNIOR, A. A.; NUNES, D. G.; BERTOLDI, F. K.; PALHANO, M. N.; KOMIEKIEWICZ, N. L. K. Pão de ora-pro-nóbis: um novo conceito de alimento funcional. Revista Agropecuária Catarinense, v. 23, n. 1, p. 35-37, 2010.

SWAIN, T.; HILLIS, W. E. The phenolic constituents of Prunus domestica. Journal of the Science and food Agriculture, v. 10, n.1, p. 63-68, 1959.

TAKEIT, C. Y.; ANTONIO, G. C.; MOTTA, E. M. P.; COLARES-QUEIROZ, F. P.; PARK, K. J. Nutritive evaluation of a non-conventional leafy vegetable (Pereskia aculeata Miller). International Journal of Food Science and Technology, Campinas, v. 1, n. 60, p. 148-160, 2009.

TOFANELLI, M. B. D.; RESENDE, S. G. Sistemas de condução na produção de folhas de ora-pro-nobis. Pesquisa Agropecuária Tropical, Goiânia, v. 41, n. 3, p. 466-469, 2011.

VALENTE, L. M. M.; SCHEINVAR, L. A.; SILVA, G. C. da; ANTUNES, A. P.; SANTOS, F. A. L. dos; OLIVEIRA, T. F.; TAPPIN, M. R. R.; AQUINO NETO, F. R.; PERIERA, A.S.; CARVALHAES, S. F.; SIANI, A. C.; SANTOS, R. R.; SOARES, R. O. A.; FERREIRA, E. F.; BOZZA, M.; STUTZ, C.; GIBALD, $D$. Evaluation of the antitumor and trypanocidal activities and alkaloid profile in species of Brazilian Cactaceae. Pharmacognosy Magazine, Mumbai, v. 3, n. 11, p. 167-172, 2007.

\section{Histórico editorial}

Submetido em: 05/03/2014

Aceito em: 23/01/2015 